\title{
CAPACITAÇÃO PEDAGÓGICA: UMA CONSTRUÇÃO SIGNIFICATIVA PARA O ALUNO DE GRADUAÇÃO*
}

\author{
Eliana Aparecida Villa** \\ Matilde Meire Miranda Cadete***
}

VILLA, E.A.; CADETE, M.M.M. Capacitação pedagógica: uma construção significativa para o aluno de graduação.

Rev.latino-am.enfermagem, Ribeirão Preto, v. 9, n. 1, p. 53-58, janeiro 2001.

Este trabalho descreve a estruturação da disciplina "Capacitação Pedagógica" do novo Currículo de Enfermagem, da Escola de Enfermagem da Universidade Federal de Minas Gerais. Consideramos que cursar essa disciplina pedagógica, proporciona ao aluno a oportunidade de ser sujeito ativo e arquiteto do seu conhecimento, podendo desenvolver, intencionalmente, o seu papel de educador e atuar de maneira crítica, visando a realidade dos envolvidos. Podemos dizer que, a capacitação pedagógica constitui uma das possibilidades para se pensar, refletir e reconstruir o processo ensino-aprendizagem, tanto nos momentos vividos em sala de aula, quanto nos campos de prática assistencial.

UNITERMOS: ensino, enfermagem, educação

\section{INTRODUÇÃO}

Como docentes da Escola de Enfermagem da Universidade Federal de Minas Gerais, temos verificado a necessidade de conscientizar os alunos quanto à importância em assumir, como enfermeiros, o papel de educador, que por diversas vezes, tem sido relegado. No decorrer das disciplinas, identificamos também, uma grande dificuldade no ensino de enfermagem, um ensino funcionalista, centrado na doença, no qual o aluno é muito mais instigado a pensar as questões do patológico e quase nada na sua função como educador para a saúde.

Em nossa prática docente, verificamos dificuldades comuns aos alunos, que BRUSILOVSCKY (1989, p.35) aponta como dificuldades que as carências educativas provocam no adulto tais como: dificuldade para analisar o seu meio social ou questões relacionadas à profissão; dificuldade para expressar-se; dificuldade para orientar-se frente às diferentes fontes de informação, às quais acrescenta-se a dificuldade na expressão escrita. Vimos, então, pensando de que maneira auxiliar esse aluno a desenvolver seu potencial.

Enfermeiros, estudando um modelo pedagógico para a Educação à Distância na América Latina (REAL, 1995), analisam os elementos que afetam o funcionamento dos programas educativos, enfatizando que estes também são verificados no ensino da graduação em enfermagem, tais como: resistência de alguns docentes em aceitar concepções pedagógicas que estimulem o desenvolvimento da consciência crítica dos alunos, atribuindo-se esse fato à influência de métodos mais tradicionais, ou ainda, à percepção de que o desenvolvimento crítico e capacidade de buscar o conhecimento, geram uma perda do poder docente; utilização de uma escassa variedade de métodos por desconhecimentos da parte destes; desinteresse do próprio aluno, diante da responsabilidade e trabalho na autoaprendizagem, em função de estarem acomodados ao papel de meros receptores; rigidez das instituições acadêmicas que dificultam ou não apoiam propostas de mudanças.

Diante de tal realidade, esse estudo tem por objetivo, elaborar a disciplina Capacitação Pedagógica, repensando a prática docente, verificando quais estratégias permitiriam, ao aluno, oportunidades para que seja ativo na construção do seu saber, e assim podermos formar um profissional capaz de exercer seu papel de educador, atuando criticamente na realidade onde se insere.

\footnotetext{
* Trabalho apresentado no $51^{\circ}$ Congresso Brasileiro de Enfermagem e $10^{\circ}$ Congresso Panamericano/1999

** Professor-Auxiliar do Departamento de Enfermagem Aplicada da Escola de Enfermagem da Universidade Federal de Minas Gerais. Mestranda em enfermagem. Endereço: Rua: Monsenhor Horta, 476 - Calafate - 30480-120 - Belo Horizonte - Minas Gerais - Brasil

*** Professor Adjunto do Departamento Materno-Infantil da Escola de Enfermagem da Universidade Federal de Minas Gerais. Doutora em enfermagem
} 
REFERENCIAL TEÓRICO

O enfermeiro, apesar de atender a expressivas necessidades sociais, de acordo com SAUPE (1992), tem limitada consciência de sua função social, fato este causado pelo ensino da enfermagem, tal qual vem se constituindo desde seu início, não conseguindo desvincular-se do modelo médico funcionalista. Segundo a autora, as escolhas das práticas pedagógicas dos docentes, refletem na atividade do profissional, mostrando que o distanciamento do enfermeiro da função educativa, está relacionado à sua formação.

Nas últimas décadas, as concepções pedagógicas têm valorizado um ensino mais centrado no processo do aluno, na aprendizagem e menos no processo do ensino. Nesse sentido, BORDENAVE (1994, p.20), coloca que todos os processos educativos, assim como suas metodologias e meios, têm por base uma determinada pedagogia, isto é, uma concepção de como se consegue que as pessoas aprendam alguma coisa e, a partir daí, modifiquem o seu comportamento. Conforme o autor, a escolha da pedagogia de ensino a ser utilizada, vai determinar conseqüências sobre a conduta individual, bem como sobre o comportamento social do aluno. Assim sendo, fica evidenciado que a adoção de uma postura reflexiva do aluno diante do objeto a ser estudado, permite um maior desenvolvimento deste indivíduo, tornando-o um ente capaz de decisões e posicionamentos diante das dificuldades.

É importante ressaltar que as teorias da educação que vêm embasar as concepções pedagógicas, adotadas num determinado contexto, num determinado período da história, nem sempre refletem as ideologias e objetivos desse contexto. Algumas delas surgem exatamente com o objetivo de romper com o que está estabelecido.

Para DURKHEIM (1978), a escola é o meio pelo qual é possível ao indivíduo adentrar na sociedade. Seria função portanto, da educação, transformar esse ser individual e vazio, em um ser social. O homem seria assim, uma tabula rasa, sobre a qual se inscreveria todo o saber, determinando no processo ensino-aprendizagem, uma relação unilateral, na qual somente o professor é detentor do conhecimento. Essa teoria traduz o que BORDENAVE (1994) chama de pedagogia da transmissão.

A partir das teorias evolucionistas, conforme relata SAUPE (1992), o escolanovismo vai se concretizar com a proposta pedagógica de Dewey. Muito embora o movimento da "escola-nova" não desenvolvesse um pensamento único, mostrava-se coeso no sentido de contrapor-se à escola tradicional. Assim, segundo TEIXEIRA (1978), descrevendo a pedagogia de Dewey, o centro deixa de ser o professor como o detentor do saber e passa a ser o aluno, suas experiências; os programas e métodos, centrados no interesse do educando. $\mathrm{O}$ processo ensino-aprendizagem dar-se-ia mediante a reconstrução das experiências e através dessa reconstrução, caminhar-se-ia para a transformação social.

Também fazendo parte desse movimento, num momento mais contemporâneo, SNYDERS (1988) vem contribuir, trazendo novas propostas, segundo as quais, o ensino deve ser renovado a partir de uma renovação dos conteúdos culturais. Considera fundamental a questão da cultura primeira que o aluno traz consigo ao chegar na escola, que deve ser trabalhada, lapidada, ampliada com o auxílio do professor. Este é, então, o facilitador do processo ensino-aprendizagem, que vai ocorrer num movimento de interestruturação, no qual ambos, professor e aluno interagem e sofrem modificações.

Assim, dentre as diversas teorias estudadas, consideramos que a abordagem sócio-cultural de Paulo Freire pode nortear nosso trabalho, de modo que, optando por uma nova ordem pedagógica, possamos auxiliar na formação e prática do futuro enfermeiro.

Segundo FREIRE (1979, p.28), a educação implica numa busca contínua do homem em ser mais, portanto o homem deve ser sujeito de sua própria educação. Não pode ser objeto dela. Por isso ninguém educa ninguém! Assim, a educação pode tornar-se um caminho de libertação na construção de uma sociedade mais humana, procurando possibilitar o desenvolvimento de uma consciência crítica, que recusa as posições passivas (FREIRE, 1983).

Gadotti, em seu prefácio à obra de FREIRE (1979), aponta que os temas conscientização e mudança estão presentes em todos os seus trabalhos, ressaltando o papel da educação, como meio através do qual a conscientização vai ocorrer. Para Freire, não se deve ter uma visão ingênua da escola como espaço e tempo para a constituição do conhecimento e segundo declara, em entrevista concedida a TORRES (1997), que a escola é um espaço de luta entre classes. Discutindo essa questão, salienta o papel do educador, a partir da posição que este assume diante do conflito social e atesta a importância dos conteúdos das disciplinas e a maneira como os utiliza, propiciando ou não, a manutenção da estratificação social.

Refletindo a respeito da história do nosso povo, das dificuldades do setor saúde e da formação do enfermeiro, percebemos que o homem a ser assistido, freqüentemente fica à margem do atendimento, sem participar deste. É do começo ao fim, “um paciente". Não tem direito à educação, à saúde, quiçá a ser um cidadão. Do mesmo modo, o enfermeiro, com dificuldades, vem se posicionando na estrutura institucional, saindo do lugar de submissão há muito ocupado na hierarquia organizacional. Finalmente, percebemos o estudante de 
enfermagem, na maioria das vezes, assumindo um papel passivo no processo ensino-aprendizagem, habituado a receber tudo pronto, como um desconhecedor, reconhecendo o professor como único detentor do saber. São eles, de acordo com a situação, os oprimidos (pacientes, enfermeiros, alunos) e opressores (governantes, instituições de saúde, professores) que constituem nossa sociedade, como bem analisa FREIRE (1983) em sua obra.

Diante dessa realidade, ressaltamos os aspectos humanista e crítico do pensamento Freireano, uma vez que, acima de tudo respeita o homem no seu modo de ser, no seu sendo; como um ser de relações, temporalizado e situado, um ser inacabado, que guarda em si conotações de pluralidade, de criticidade, de conseqüencia e de temporalidade (FREIRE, 1979, p.62).

Sob essa ótica, nós, docentes, não pensamos o processo ensino-aprendizagem como ato de depositar, de acumular e passar informações, bem como de transferir valores, concepção que FREIRE (1983, p.67) denominou como "bancária". Assumimos uma concepção, na qual os educandos vão desenvolvendo o seu poder de captação e de compreensão do mundo que lhes aparece, em suas relações com ele, não mais como uma realidade estática, mas como uma realidade em transformação, em processo...Servindo à libertação, se funda na criatividade, estimula a reflexão e a ação dos homens sobre a realidade (FREIRE, 1983, p.82-3).

De acordo com a concepção acima descrita, tanto o educador, quanto o educando, aprendem com a realidade, na realidade da relação ensino-aprendizagem. Educador-educando estabelecem uma relação dialógica, na qual ambos se fazem sujeitos do seu processo, superando o intelectualismo alienante, superando o autoritarismo do educador bancário (FREIRE, 1983, p.86). Aqui, o professor não é o detentor do saber, é quem sabe, mas não sabe tudo. É fundamentalmente aquele que cria condições para desenvolver a consciência crítica do aluno. Uma consciência voltada para análise de problemas; capaz de substituir explicações mágicas pela busca de princípios autênticos e de causalidade; que refuta as posições quietistas; que é questionadora, ama o diálogo e dele se nutre (FREIRE, 1979, p.41).

É uma proposta desafiadora que enfrentamos, estando cientes que nenhuma teoria se esgota em si mesma.

Finalizando esse referencial, é importante lembrar que a disciplina Capacitação Pedagógica, faz parte do Currículo Novo de Graduação em Enfermagem, que está sendo implantado, tendo sido elaborada com base no Marco Conceitual da Mudança Curricular da EEUFMG (UNIVERSIDADE FEDERAL DE MINAS GERAIS. ESCOLA DE ENFERMAGEM, 1995).

\section{DESENVOLVIMENTO}

\section{Disciplina capacitação pedagógica: sua construção}

A proposta de elaboração da Capacitação Pedagógica teve origem a partir do conhecimento e discussões de diferentes teorias da educação, de maneira a dar sustentação necessária à condução de uma nova concepção e resumidas no referencial apresentado. Consideramos a importância em validar esse aprendizado, utilizando-o na nossa prática docente, através de um plano de trabalho a ser desenvolvido na nova disciplina, a ser implantada.

Segundo MIZUKAMI (1986, p.98), a ação do homem sem objetivos, não constitui praxis, e sim uma ação ignorante de sua finalidade. Assim, para nortear o desenvolvimento da disciplina, partimos da elaboração dos seus objetivos, descritos a seguir:

\section{Objetivos}

- Propor experiências de aprendizagem de modo a desenvolver a consciência crítica do aluno de enfermagem.

- Possibilitar ao aluno a análise de seu fazer pedagógico e suas implicações.

- Conscientizar o aluno de enfermagem da importância do papel de educador, a ser assumido na sua vivência profissional.

- Capacitar o futuro enfermeiro a exercer as funções educativas, voltando-as para uma ação transformadora.

\section{Desenvolvimento}

Fundamentadas no referencial teórico, buscando atingir os objetivos propostos, estruturamos o desenvolvimento da disciplina em unidades norteadoras das atividades a serem executadas pelos alunos, conforme apresentamos:

\section{UNIDADE 1}

- pesquisar e estabelecer diferenças entre as principais concepções pedagógicas.

- analisar os conceitos de ensino-aprendizagem que norteiam as diferentes concepções.

- discutir as conseqüências da utilização de cada uma destas.

\section{UNIDADE 2}

- identificar em quais situações o enfermeiro exerce a função educativa.

- pesquisar e discutir, como o profissional vem desenvolvendo essa função.

- examinar e justificar qual concepção pedagógica mais 
se aproxima da prática educativa do enfermeiro, estabelecendo suas conseqüências.

- elaborar possibilidades de solução para os problemas identificados.

- analisar a importância do papel do enfermeiro como educador na área da saúde.

- apresentar e discutir uma metodologia de ação educativa em saúde.

\section{UNIDADE 3}

- escolher e identificar o ambiente para ação educativa.

- conhecer e confrontar as diferentes abordagens de pesquisa para o estudo exploratório.

- elaborar, aplicar e analisar instrumento para caracterização da população envolvida.

- identificar aspectos culturais, sociais, políticos da população, bem como o tema de interesse a ser trabalhado na ação educativa.

\section{UNIDADE 4}

- pesquisar, discutir e utilizar técnicas de ensinoaprendizagem.

- selecionar conteúdos e técnicas apropriados para a prática educativa.

- criar recursos didáticos de modo a propiciar melhor aproveitamento dos envolvidos.

- elaborar, desenvolver e avaliar ação educativa, estabelecendo relação entre os objetivos e os meios selecionados para sua execução.

- analisar o processo educativo vivenciado na disciplina, comparando-o com os objetivos propostos inicialmente.

\section{Seleção dos conteúdos}

A próxima etapa diz respeito à seleção de conteúdos e para tal, partimos do pressuposto de que não basta a seleção de um conjunto de informações e teorias a serem depositadas no educando, como na educação bancária. A seleção de conteúdos visa a organização do conhecimento a ser construído durante a disciplina, de modo a nortear o aluno na busca do seu aprendizado, atendendo aos objetivos propostos para cada Unidade. Lembramos ainda que, segundo MIZUKAMI (1986, p.106) o papel da teoria é muitas vezes limitado, não abordando alguns aspectos do processo educativo, sendo que esta incompletude pode servir de guia ou fornecer elementos para a reflexão. Deseja-se assim, levar o educando a aprender, colocando-se como alguém em busca constante do conhecimento, que não se esgota nos programas de disciplinas, tornando-se sujeito de sua própria educação (FREIRE, 1979, p.28).

Para DILLY \& JESUS (1995), os conteúdos são instrumentos para que os alunos possam atingir os objetivos propostos, considerando-se a realidade, a situação e o período em que ocorrem. De acordo com as autoras, todo conteúdo traz em si um conjunto de valores, não havendo neutralidade. Essa ausência de neutralidade foi apresentada anteriormente, ao descrevermos a visão Freireana quanto aos conteúdos. Podemos verificar então, que não basta questionar "o quê", do conteúdo a ser ensinado e "o como", mas também em função de quais interesses eles servem. Pensamos pois, que é papel do professor, estimular os alunos a desenvolverem, através dos conteúdos, sua capacidade de interpretação, reflexão e crítica, relacionando-os com a realidade prática para a qual se destinam.

Outra característica da seleção de conteúdos é a flexibilidade. Assim, essa seleção deve estar sujeita a modificações, adaptações, renovações $e$ enriquecimento...sempre que for necessário de acordo com as necessidades e novas situações que surgem no dia a dia do estudante (DILLY \& JESUS, 1995, p.146). Portanto, o conteúdo não tem um caráter imutável, devendo ser constituído dentro de um contexto próprio, envolvendo professor e aluno no aprendizado do mesmo objeto.

Finalizando, na organização dos conteúdos, é importante ainda, segundo DILLY \& JESUS (1995), considerar os pré-requisitos e pós-requisitos, tais como: o grau de conhecimento necessário na formação do profissional, o grau de desenvolvimento intelectual ou cognitivo do aluno e os graus de complexidade do conteúdo. Observa-se ainda a necessidade de que os temas mantenham relação uns com os outros, integrando-se de modo a formar um conjunto.

\section{Estratégias de ensino-aprendizagem}

O passo seguinte está relacionado ao "como" esses temas serão trabalhados. Na disciplina Capacitação Pedagógica, teoria e prática são trabalhadas de maneira integrada, de modo que o aluno esteja o tempo todo relacionando o conhecimento na construção do seu desempenho prático. Desta forma, é necessária uma experiência vivida, e esta por sua vez, deverá estar ligada à realidade profissional do aluno.

Quanto às técnicas de ensino-aprendizagem a serem utilizadas, LOPES (1996) coloca que uma alternativa para a dinamização do aprendizado seria a variação das técnicas; outra, seria a introdução de inovações nas técnicas já conhecidas.

Segundo ARAÚJO (1996, p.25), a técnica é um conjunto de processos, uma arte que designa sempre uma atividade prática, diferentemente da ação de compreender. Ela tem um caráter instrumental, estruturante do método de ensino. $\mathrm{O}$ autor complementa dizendo que as técnicas intermediam as relações entre o professor e o aluno, são mediações, ou condições necessárias e favoráveis, mas 
não suficientes do processo de ensinar. Assim, as técnicas servem às diferentes concepções, dependendo de como são utilizadas, podendo estar a serviço da manipulação, do tecnicismo, da perspectiva libertadora. Não é suficiente, portanto, conhecê-las teoricamente; é na maneira de usá-las que se vai definir seu potencial.

Em alguns momentos serão usadas técnicas mais centradas no professor, como é o caso da exposição e da demonstração; em outros, técnicas mais centradas no aluno, tais como o estudo de texto, a pesquisa bibliográfica; em outros ainda, técnicas mais centradas na socialização, como o seminário, a discussão, o debate e o trabalho prático em grupo. Em todos os casos, sua utilização deverá estar voltada para a construção do aprendizado do aluno, pelo próprio aluno, tendo no professor aquele que orienta esse processo e não o domina. Resgatando a teoria de SNYDERS (1988), podemos dizer que o trabalho do professor é caracterizado por duplo movimento: continuidade de experiência trazida pelo aluno e ruptura dessa experiência, propiciando-lhe uma visão mais elaborada do conhecimento. É, à medida que o professor contribui para formar no aluno o pensamento crítico e criador, ele estará dando sua parcela de contribuição para que estes busquem soluções para os problemas detectados e ao mesmo tempo os habilite para enfrentar outros.

É importante lembrar que, de acordo com ARAÚJO (1996), a técnica em si não se sustenta, deve ser concebida como encadeada a outras técnicas e a outros elementos do processo pedagógico. Dessa forma, quando falamos em exposição está implícita a discussão, o questionamento; quando usamos o seminário, dependemos do estudo de texto, do debate e assim por diante.

\section{Processo avaliativo}

A próxima etapa diz respeito ao processo avaliativo, que deverá ocorrer durante toda a disciplina, e não apenas ao final desta. Segundo CALDEIRA (1997, p.53) a avaliação subsidia a construção do processo do ensino porque fundamenta novas decisões. Portanto, conforme colocado anteriormente, a estruturação da disciplina deve ser flexível, de modo a possibilitar mudanças, de acordo com o processo contínuo de avaliação.

Nesse sentido, CALDEIRA (1997, p. 60) coloca que a avaliação deve ser contínua, reveladora de toda trajetória do estudante e não centrada apenas no produto...não bastam as provas, é necessário buscar novos instrumentos, sempre ligados aos objetivos definidos (trabalhos, entrevistas, conversas, observações práticas, entre outros). Na mesma perspectiva, SAUL (1995, p.63) propõe que as avaliações sejam realizadas numa abordagem qualitativa, na qual não são desprezados os dados quantitativos, mas a ótica de análise é eminentemente qualitativa. Segundo a autora, sob esse prisma, o docente assume o papel de coordenador dos trabalhos avaliativos e de um orientador dessas ações, cuja tarefa é promover situações que favoreçam o diálogo, a discussão, a busca e a análise crítica sobre o seu desenvolvimento.

DILLY \& JESUS (1995), colocam como princípios básicos da avaliação, o estabelecimento claro do que vai ser avaliado, seleção de técnicas adequadas, determinação dos critérios e condições para avaliação, como também, a consciência das possibilidades e limitações do processo avaliativo.

Por fim, propomos para esta disciplina, uma avaliação contextualizada na realidade social e cultural dos envolvidos, a ser trabalhada junto aos alunos. O compromisso principal desta avaliação, é o de fazer com que os envolvidos, direta e indiretamente, na ação educacional escrevam a sua "própria história" e construam as suas próprias alternativas de ação (SAUL, 1995), num processo assumido em parceria, pelo docente e pelo aluno.

\section{CONSIDERAÇÕES FINAIS}

Ao elaborarmos a disciplina Capacitação Pedagógica, esperamos possibilitar o desenvolvimento do aluno como um todo, favorecendo sua motivação e interesse pela temática proposta.

Na sua prática profissional, o enfermeiro terá que exercer seu papel de educador, visando objetivos específicos que não podem estar descontextualizados da realidade dos envolvidos. Essas ações educativas exigem, portanto, a participação intencional do profissional, que deve ter preparo suficiente para atuar como agente transformador.

A formação do enfermeiro requer pois, ênfase na reflexão e construção de uma consciência crítica, buscando no confronto com a realidade vivida, o conhecimento necessário para a solução dos problemas.

Finalizando, fazemos uso das palavras de DILLY \& JESUS (1995, p.178)... precisamos ser estimulados para superar o sentimento de descrença que impede o esforço para concretização de mudança. O primeiro passo para caminhar em direção à mudança é acreditar que ela é possivel, é construída gradativamente e ainda, reconhecê-la infinita. Estamos certos que demos o primeiro passo rumo a um longo caminho a ser construído e compartilhado entre alunos e docentes, durante a experiência vivida no processo ensino-aprendizagem dessa disciplina. 
This work describes the structure of the course "Pedagogical Training" introduced in the new Nursing Curriculum of Minas Gerais Federal University College of Nursing. We believe that attending this pedagogical course provides students with the opportunity to be the active subjects and architects of their own knowledge, which will make it possible for them to deliberately develop their roles as educators and perform in a critical manner in view of the reality of those involved. It can be said that pedagogical training constitutes one of the possibilities to think about, reflect on and construct the teaching-learning process during both the moments experienced in class and those in the fields of clinical practice.

\section{CAPACITACIÓN PEDAGÓGICA: UNA CONSTRUCCIÓN SIGNIFICATIVA PARA EL ALUMNO DE PREGRADO}

Este trabajo describe la estructuración de la materia "Capacitación Pedagógica" del nuevo Curriculum de Enfermería, de la Escuela de Enfermería de la universidad Federal de Minas Gerais. Consideramos que cursar esta materia pedagógica, proporciona al alumno la oportunidad sujeto activo y arquitecto de su conocimiento, pudiendo desarrollar intencionalmente, su papel de educador y actuar de manera crítica, buscando la realidad de los comprometidos. Podemos decir que, la capacitación pedagógica constituye una de las posibilidades para pensar, reflexionar y construir el proceso enseñanza-aprendizaje, tanto en los momentos vividos en la sala de aula cuanto en los campos de práctica asistencial.

TÉRMINOS CLAVES: enseñanza, enfermería, educación

\section{REFERÊNCIAS BIBLIOGRÁFICAS}

01. ARAUJO, J.C.S. Para uma análise das representações sobre as técnicas de ensino. In: VEIGA, I.P.A (org.). Técnicas de ensino: porque não? 4 . ed. Campinas, SP: Papirus, 1996. p. 08-34.

02. BORDENAVE, J.D. A transferência de tecnologia apropriada ao pequeno agricultor (adaptado para Grandi). In: BRASIL. Ministério da Saúde. Capacitação pedagógica para instrutor/ supervisor - Área da Saúde. Brasília: Ministério da Saúde, 1994. p. 19-26.

03. BRUSILOVSCKY, S Treinamento mental: um método para um enfoque à educação de adultos. In: BRASIL. Ministério da Saúde. Capacitação pedagógica para instrutor/supervisor - Área da Saúde. Brasília: Ministério da Saúde, 1994. p. 35-38.

04. CALDEIRA, A.M. Avaliação e processo de aprendizagem. Presença pedagógica. Belo Horizonte: Dimensão, v. 3, n.17, p. 53-61, set./ out. 1997.

05. DILLY, C.M.L.; JESUS, M.C.P. Processo educativo em enfermagem: das concepções pedagógicas à prática profíssional. São Paulo: Robe , 1995. $190 \mathrm{p}$.

06. DURKHEIM, E. Educação e Sociologia. São Paulo: Melhoramentos, 1978. p.33-56.

07. FREIRE, P. Educação e mudança. 16. ed. Rio de Janeiro: Paz e Terra, 1979.

08.

Pedagogia do oprimido. 14. ed. Rio de Janeiro: Paz e Terra, 1983. 220 p.
09. LOPES, A.O. Aula expositiva: superando o tradicional. In: VEIGA, I. P. A (org.). Técnicas de ensino: Porque não? 4. ed. Campinas, SP: Papirus, 1996. p. 35-48.

10. MIZUKAMI, M.G.N. Ensino: as abordagens do processo. São Paulo: EPU, 1986. 119p.

11. REAL, Rede de Enfermeria de América Latina. Um modelo pedagógico para la educacion a distancia. Belo Horizonte, set/1995. n, 2, 23p. (Publicaciones REAL, série educacion).

12. SAUL, A..M. Avaliação emancipatória: desafio à teoria e à prática de avaliação e reformulação do currículo. 3. ed. São Paulo: Cortez, 1995. p. 5374.

13. SAUPE, R. Ensinando e aprendendo a Enfermagem - A transformação possível. São Paulo, 1992. 200 p. Tese (Doutorado) - Escola de Enfermagem, Universidade de São Paulo.

14. SNYDERS, G. A alegria na escola. São Paulo: Manole, 1988. p. 87-107.

15. TEIXEIRA, A. A Pedagogia de DEWEY. In: DEWEY, J. Vida e Educação. São Paulo: Melhoramentos, 1978. p. 14-41.

16. TORRES, C.A. O homem que amava intensamente. Pátio Rev. Pedagógica. v. 1, n. 2, p. 32-37, ago./ out. 1997.

17. UNIVERSIDADE FEDERAL DE MINAS GERAIS. ESCOLA DE ENFERMAGEM. Proposta de mudança curricular. Belo Horizonte, 1995. 35p. (mimeo.). 